\title{
Direito administro adjetivo ${ }^{1}$
}

Carlos Francisco Borges Ferreira Pires

\section{Resumo}

O Processo Administrativo, tão presente nas mais variadas áreas de atuação da Administração Pública, teve posição elevada a partir de 29 de Janeiro de 1999 com o surgimento no ordenamento pátrio da Lei 9.784 que consagrou o processo administrativo no âmbito da Administração Pública Federal. Alguns autores entendem que o ponto focal de estudo do Direito Administrativo não é a própria Administração, mas sim, a posição que ocupa os administrados perante ela, como corolário, mais importante e relevante foi o advento da já referida lei uma vez que, pelo seu texto, os administrados passam a ocupar posição mais participativa no desenvolvimento das atividades da Administração.

Palavras-Chave: Processo Administrativo; Lei 9.784/99; Administrados; Administração Pública.

\section{Introdução}

O presente trabalho busca apresentar uma síntese de o que vem a ser o processo administrativo; tema ainda pouco discutido pela doutrina, mas de importância imensurável para o alcance do bem comum.

Feliz fora o legislador que, pela necessidade apresentada pelos fatos, através do advento da Lei 9.784 de 29 de Janeiro de 1999, conscientizou-se que a Administração Pública atua através de uma série de atos, pelos quais muitas vezes, esbarram em uma unilateralidade extrema chegando ao arbitrarismo. Por este motivo, estes atos devem ser organizados, então, por um procedimento adequado.

Os administrados, por sua vez, participam cada vez mais da Administração merecendo respaldo dos princípios da ampla defesa e contraditório, como sendo isto indispensável para o verdadeiro Estado Democrático de Direito. Como salienta o professor Romeu Felipe Bacellar Filho:

1 Trabalho vencedor do prêmio Hely Lopes Meirelles no Concurso de Artigos Jurídicos realizado em 12 de Novembro de 2004 pelo Instituto Paranaense de Direito Administrativo durante o V Congresso Paranaense de Direito Administrativo 
O processo administrativo - enquanto garantia constitucional - possibilita a regularização do exercício da competência (garantia geral de estrutura do ordenamento jurídico), servindo dessa forma como instrumento de proteção do indivíduo perante a ação daquela competência. Na relação entre Administração e cidadãos, técnicas processuais tutelam competências para aquela e direitos e liberdades para estes. ${ }^{2}$

Com estes parâmetros em mente, iniciaremos nossa tarefa.

\section{Função jurisdicional do Estado}

Dentre as várias funções atinentes ao Estado, talvez a mais humana seja a função jurisdicional; não somente por estar mais próxima da sociedade, mas por ser a função que mais se exterioriza na concepção leiga dos litigantes.

Sem desmerecer as outras funções, como a legislativa e a administrativa, a função jurisdicional vai até o campo de batalha tendo como único fito dirimir o conflito estabelecido pelas diferenças de interesse entre as partes e, com isso, atingir o bem comum, que por sua vez, pode ser visto, direta ou indiretamente, como sendo o objetivo de todas as outras funções do Estado.

\section{Processo administrativo}

Como primeira observação a ser desenvolvida cabe questionar o emprego do vocábulo processo ou procedimento administrativo.

Tema muito discutido na doutrina, o emprego da expressão procedimento administrativo é defendida por autores como Maria Sylvia Zanella Di Pietro e Lúcia Valle Figueiredo. Entende a professora Lúcia que, o processo é a forma pela qual o Estado atua em todas suas funções, ressaltando que, no procedimento administrativo, sempre haverá processo. $^{3}$

Para outros autores como Celso Antônio Bandeira de Mello, mais correto é o emprego da terminologia processo administrativo. Em suas palavras:

2 FILHO, Romeu Felipe Bacellar. Princípios Constitucionais do Processo Administrativo Disciplinar. São Paulo: Max Limonad, 1998, p. 60.

3 FIGUEIREDO, Lúcia Valle. Curso de Direito Administrativo. São Paulo: Malheiros, 1994. p. 280. 
Sem embargo, cremos que a terminologia adequada para designar o objeto em causa é 'processo', sendo 'procedimento' a modalidade ritual de cada processo. É provável, ou menos muito possível, que a partir da lei federal, em sintonia com ela, comece a disseminar no País a linguagem "processo". 4

De toda a sorte, para nós, data vênia nobres professores, mais correto seria a utilização da expressão processo administrativo, pois procedimento, como entende parte da doutrina, é a série 'de atos que, juntos, formam o processo; e, por ser também fiel ao texto constitucional, que traz disposto tal terminologia no art. 5ํ, LV da Carta Magna de 1988.

Porém, é cabível ressaltar que, todo processo é composto por atos que formam o procedimento, mas, a recíproca se faz errônea como orienta o ilustre professor Hely Lopes Meirelles, quando salienta que existem procedimentos administrativos que não constituem processo como, por exemplo, os de licitação ou concurso.

\section{Conceito}

Pode-se conceituar o processo administrativo como sendo uma sucessão itinerária e encadeada de atos administrativos que tendem, todos, a um resultado final e conclusivo. ${ }^{5}$

Para o professor Hely Lopes Meirelles, a Administração Pública, para registro de seus atos, controle da conduta de seus agentes e soluções de controvérsias dos administrados, utiliza-se do processo administrativo. ${ }^{6}$

Por não serem os conceitos construídos unicamente por um axioma, e sim por um conjunto de idéias e detalhes observados por uma gama diversificada de estudiosos, cabe apresentar o conceito trazido por Cretella Júnior:

Processo administrativo é o conjunto de iniciativas e diligências praticadas pelo órgão competente para apurar fatos ou desempenhos - atribuídos a quaisquer pessoas físicas, jurídicas ou entes despersonalizados - que atingem bens juridicamente protegidos, instaurando-se, para tanto, o mais breve possível, seja de ofício, mediante representação ou após investigações preliminares, caso existam, culminando com o arquivamento ou com decisão fundamentada do órgão julgador. $^{7}$

4 BANDEIRA DE MELLO, Celso Antônio. Curso de Direito Administrativo. 15. ed. São Paulo: Malheiros, 2003. p. 443.

Idem. p. 442.

MEIRELLES, Hely Lopes. Direito Administrativo Brasileiro. 28. ed. São Paulo: Malheiros, 2003. p. 655.

CRETELLA JR., José. Comentários à Lei Antitruste. Rio de Janeiro, Forense, 1996. p. 103. 


\section{Princípios}

Matéria introdutória das mais diversas ciências, a principiologia merece verdadeiro destaque no tocante à sua importância como alicerce dentro da dogmática jurídica. Através do estudo dos princípios é possível chegar ao grau máximo de interpretação do texto legal, bem como à solução de conflitos decorrentes de suas lacunas.

Por seu caráter basilar, exteriorizam-se em dois momentos: na realização das leis e na aplicação do Direito. Quando se disciplina uma determinada ordem de interesse social, a autoridade competente não caminha sem um roteiro predelineado. $O$ ponto de partida para a composição de um ato legislativo, por exemplo, deve ser o da seleção dos valores e princípios que se quer consagrar, que se deseja infundir no ordenamento jurídico. ${ }^{8}$

Os princípios, nas palavras do professor Humberto Ávila, estabelecem os fins a serem buscados. ${ }^{9}$

A principiologia, dentro do tema em estudo, deve ser dividida em dois ramos para melhor compreensão. Seguindo este caminho, podem ser os princípios separados em: a) Princípios Gerais do Processo e; b) Princípios do Processo Administrativo.

Dentre os primeiros destacam-se, entre outros, os Princípios: Do Devido Processo Legal; Contraditório e Ampla Defesa; Igualdade Processual e Acesso a Justiça; Motivação e Publicidade das Decisões; Lealdade Processual; Duplo Grau de Jurisdição; Economia Processual, Verdade Material (real), Verdade Formal e Persuasão Racional do Juiz; Imparcialidade do Juiz (Juiz Natural); Da Ação, Dispositivo ou Acusatório e Impulso Oficial.

A esfera dos princípios do processo administrativo é preenchida pelos princípios constitucionais e legais do processo administrativo, óbvio não apenas estes, a dizer: Legalidade; Razoabilidade; Proporcionalidade; Motivação; Publicidade; Igualdade; Impessoalidade; Moralidade; Eficiência; Supremacia e Indisponibilidade do Poder Público; Segurança Jurídica; (aqui também) Contraditório, Ampla Defesa e Devido Processo Legal; Verdade Material e Formalismo Moderado.

Não adentraremos ao significado de cada um dos princípios acima exposto por se fazer inoportuno, uma vez que tal matéria seria, por ela mesma, digna de um verdadeiro 
tratado. Entretanto, faremos referência a alguns na medida em que o assunto adentrar em suas esferas de preceitos.

\section{Classificação}

Os processos administrativos possuem uma extensa gama de critérios para sua classificação. Podem ser classificados em: de interesse público ou de interesse particular; processos internos ou externos; primários ou secundários. ${ }^{10}$

Conforme o próprio objetivo do processo, como o próprio nome já induz o entendimento, podem ter natureza coletiva ou singular.

São internos quando realizados no âmbito da Administração Pública através da utilização de seus órgãos e externos quando realizados entre esta e seus administrados.

Por fim, são primários aqueles que se destinam à prática de qualquer ato administrativo e; secundários, aqueles que têm como objetivo somente a reavaliação desses atos.

\section{Fases do processo administrativo}

O processo administrativo se desenvolve, sucessivamente, em cinco fases distintas: a) instauração; b) instrução; c) defesa; d) relatório e; e) julgamento.

O processo administrativo próprio, ou seja, aquele incumbido de sanar conflito entre Administração Pública e seus administrados, se compõe, na maior parte das vezes, das cinco fases acima apresentadas. Vejamos, mesmo que de forma sucinta, cada uma delas:

A instauração é o início do processo através da apresentação escrita dos fatos narrados. Advindos da Administração Pública, exteriorizam-se em Portarias, Autos de Infração e Despachos da Autoridade que detém a competência. Quando advêm dos administrados, apresenta-se através de uma petição inicial. O objetivo da fase da instauração é a maior precisão na delimitação dos fatos e do objeto do conflito. Torna-se nula o processo com imprecisão desta fase.

$\mathrm{Na}$ instrução, os fatos alegados deverão ser provados. É nesta fase que se tomarão os depoimentos das partes, as declarações das testemunhas, realizarão as perícias e serão

10 XAVIER, Alberto. Do Procedimento Administrativo, São Paulo: José Bushatsky, 1976. p. 145. 
produzidos todos os meios de prova permitidos dentro do sistema jurídico. Se houver defeito em algum momento desta fase, a invalidação do processo ou do julgamento poderá ser decretada, uma vez que, não é permitido detrimento da verdade para uma apuração isonômica de provas.

Durante a fase da defesa, tem o acusado a chance de interpor sua contestação, elaborar os contra argumentos e apresentar suas provas para tanto. É nesta fase que aparece o princípio máximo do Estado Democrático de Direito, o Princípio do Devido Processo Legal. Nos dizeres do ilustre professor Hely Lopes Meirelles, "o processo administrativo sem oportunidade de ampla defesa ou com defesa cerceada é nulo". ${ }^{11}$

Ainda é importante ressaltar que, das garantias constitucionalmente asseguradas pelo inciso LV do artigo 5o da Carta Magna de 1988 infere-se que qualquer pessoa, independentemente do processo ser judicial ou administrativo, terá o contraditório e a ampla defesa resguardados.

Em seguida, encontra-se a fase do relatório. Este, por sua vez, traz a suma do processo realizado até o momento de sua elaboração. Não é feito por um órgão julgador, mas, por uma comissão ou por aquele que presidiu o processo. Assim sendo, não é um documento com efeito vinculante para a Administração ou mesmo para os interessados no processo.

Quem realiza o julgamento necessita, obrigatoriamente, estar sob a égide da competência correspondente. O julgamento somente terá validade se proferido por quem de direito. Pode estar fundamentado no relatório como pode o julgador ater-se a outras verdades fáticas não abordadas pelo mesmo; se o julgador decidir por fatos diversos daqueles apresentados no relatório deve, todavia, fundamentá-los, como estabelece o Princípio da Motivação. Neste diapasão:

O essencial é que a decisão seja motivada com base na acusação, na defesa e na prova, não sendo lícito à autoridade julgadora argumentar com fatos estranhos ao processo ou silenciar sobre as razões do acusado, porque isto equivale a cerceamento de defesa e conduzirá à nulidade do julgamento, que não é discricionário, mas vinculado ao devido processo legal. ${ }^{12}$

11 MEIRELLES, 2003. p. 662.

12 Idem. p. 663 


\section{Finalidades do processo administrativo}

De acordo com o professor Celso Antônio Bandeira de Mello, o processo administrativo existe para atender duas necessidades principais: a) resguarda dos administrados e; b) para efetuar uma atuação administrativa mais clarividente.

Quanto ao primeiro ponto, salienta-se a possibilidade de o administrado ser ouvido antes que alguma decisão vier a afetá-lo. Trata-se de estabelecer controles internos à atuação da Administração.

Já o segundo faz referência à Administração atuar através de uma forma mais transparente, mais bem informada, auxiliando dessa maneira o descobrimento de soluções mais plausíveis por parte desta, tendo como fito o de atender ao bem comum, preservando sempre o interesse público acima do interesse privado. ${ }^{13}$

Na lição de Sérgio Ferraz e Adílson Dallari:

São finalidades do processo administrativo assegurar a produção e a eficiência do agir administrativo e maximizar as garantias do administrado. Assim sendo, o processo administrativo aberto, visível, participativo, é instrumento seguro de prevenção à arbitrariedade. ${ }^{14}$

\section{Modalidaes do processo administrativo}

São modalidades do processo administrativo: processo de expediente, processo de outorga, processo de controle e processo punitivo.

O processo de expediente recebe, erroneamente, o nome de processo, mas, na verdade, não o é. Trata-se apenas de expedientes que não geram, não alteram, nem suprimem direitos dos administrados, da Administração ou de seus servidores, apenas finalizam com a parte burocrática em questão.

O processo de outorga é aquele que se utiliza para pleitear algum direito ou alguma situação individual que alguém que se coloque perante a Administração Pública.

O processo de controle é todo aquele através do qual a Administração verifica e declara situações, direitos ou condutas de administrados ou servidores.

13 BANDEIRA DE MELLO, 2003. p. 452 e ss.

14 DALLARI, Adílson de Abreu; FERRAZ, Sérgio. Processo Administrativo, São Paulo: Malheiros, 2002. p. 25. 
O processo punitivo é aquele promovido pela Administração para a aplicação de penalidade por infração de lei, regulamento ou processo. ${ }^{15}$

O processo administrativo pode ainda ser Disciplinar ou Tributário.

Diz-se que o processo administrativo é disciplinar quando se destina a apurar as faltas cometidas pelos servidores públicos.

Encontra-se disposto nos artigos 143 e seguintes da Lei 8.112, de 11 de Dezembro de 1990. Importante ressaltar o art. 146, caput, que através de interpretação deste dispositivo, infere-se que é imprescindível em âmbito federal o processo administrativo disciplinar para aplicação das penas de suspensão superior a trinta dias, demissão, cassação de aposentadoria e disponibilidade, e destituição do cargo em comissão.

Por outro lado, o processo administrativo é tributário à medida que objetiva a apuração dos créditos tributários exigidos pela União e o procedimento de consulta sobre a forma pela qual a legislação tributária federal é aplicada. Foi instituído pelo Decreto $\mathrm{n}^{\circ}$ 70.235 de 6 de Março de 1972 e alterado por diplomas posteriores.

\section{Conclusão}

Através do presente trabalho, tentou-se realizar um apanhado geral do processo administrativo dentro do ordenamento jurídico pátrio.

Não somente apresentar, ainda que de forma sucinta, as várias peculiaridades atinentes ao processo dentro do direito administrativo, como elevar a figura do administrado perante a Administração Pública fazendo sempre referência às suas garantias constitucionalmente resguardadas, e corolário, seu direito a se defender em juízo pelos princípios do contraditório e da ampla defesa.

Com o advento da Lei 9.784 de 29 de Janeiro de 1999, o Direito Administrativo Brasileiro adquire também a qualificação de direito adjetivo e com isso engrandece, não só a figura dos administrados, como também confere digna posição de desenvolvimento da Administração.

Muito ainda há que se discutir sobre o tema pela doutrina, mas certamente, os primeiros passos já foram galgados e, salvo obstáculos naturais e importantes para o aperfeiçoamento, o Direito Administrativo atual se apresenta de forma eficaz e competente.

15 MEIRELLES, 2003. p. 663 e ss. 


\section{Referências}

ÁVILA, Humberto. Teoria dos Princípios. São Paulo: Malheiros, 2003.

BACELLAR FILHO, Romeu Felipe. Princípios Constitucionais do Processo Administrativo Disciplinar. São Paulo: Max Limonad, 1998.

BANDEIRA DE MELLO, Celso Antônio. Curso de Direito Administrativo. 15. ed. São Paulo: Malheiros, 2003.

BASTOS, Celso Ribeiro. Curso de Direito Constitucional. São Paulo: Celso Bastos Editora, 2002.

CRETELLA JÚNIOR, José. Comentários à Lei Antitruste. Rio de Janeiro: Forense, 1996.

DALLARI, Adílson de Abreu; FERRAZ, Sérgio. Processo Administrativo. São Paulo: Malheiros, 2002.

FIGUEIREDO, Lúcia Valle. Curso de Direito Administrativo, São Paulo: Malheiros, 1994.

MELLO, Shirlei Silmara de Freitas. Tutela Cautelar no Processo Administrativo. Belo Horizonte: Mandamentos, 2003.

MEIRELLES, Hely Lopes. Direito Administrativo Brasileiro. São Paulo: Malheiros, 2003.

NADER, Paulo. Introdução ao Estudo do Direito. Rio de Janeiro: Forense, 2001.

SILVA, José Afonso da. Curso de Direito Constitucional Positivo. São Paulo: Malheiros, 2001.

SUNDFELD, Carlos Ari. Fundamentos de Direito Público. São Paulo: Malheiros, 2003.

TELLES, Antônio A. Queiroz. Introdução ao Direito Administrativo. São Paulo: Revista dos Tribunais, 2000.

XAVIER, Alberto. Do Procedimento Administrativo, São Paulo: José Bushatsky, 1976.

WAMBIER, Luiz Rodrigues; ALMEIDA; Flávio Renato Correia de; TALAMINI, Eduardo. Curso Avançado de Processo Civil. São Paulo: Revista dos Tribunais, 2002. v.1. 
